\title{
Aneurisma del tronco braquiocefálico con compresión de vía aérea
}

\section{Brachiocephalic trunk aneurysm with airway compression}

\section{ABSTRACT}

Brachiocephalic trunk (BCT) aneurysms are rare but very important since they pose a significant threat to life and limbs due to the risk of rupture, embolization, or compression of the adjacent structures. We now present a case of a BCT aneurysm with tracheal compression leading to difficult ventilator weaning.

Palabras clave: Aneurisma, tronco braquiocefálico, vía aérea

Keywords: Aneurysm, brachiocephalic trunk, airway

\section{CASE}

An asymptomatic 78-year-old man with history of prostatic neoplasia, was diagnosed with a large $(45 \times 55 \mathrm{~mm})$ brachiocephalic trunk aneurysm while doing a routine CT for his cancer follow-up. He was submitted to a carotid-subclavian transposition, with posterior admission to an intensive care unit (ICU). The procedure occurred with no immediate complications, but after ICU admission the patient developed stridor and breathing effort, leading to orotracheal reintubation. The bronchoscopy revealed a pulsatile extrinsic compression $5 \mathrm{~cm}$ above the vocal cords. The cervical CT was repeated demonstrating the aneurysm compression of the trachea making it impossible to extubate the patient. After multidisciplinary discussion the team decided to proceed to endovascular aneurysm exclusion with posterior endotracheal prothesis insertion. The aneurysm exclusion was completed in a twostep procedure and the tracheal prothesis. The patient was discharged from the hospital after a 30 day stay.
Fig. 1. Large brachiocephalic trunk aneurysm with tracheal compression before (Fig. 1A) and after (Fig. 1B) aneurysm exclusion and tracheal prothesis insertion.

Fig. $1 \mathrm{~A}$
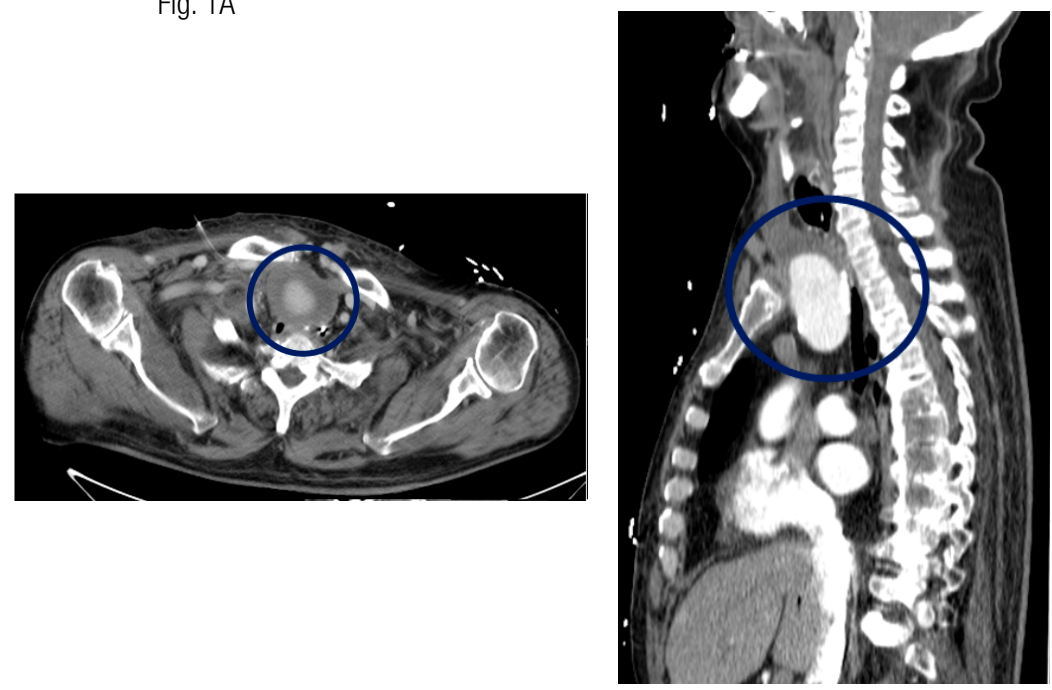

Fig. 1B
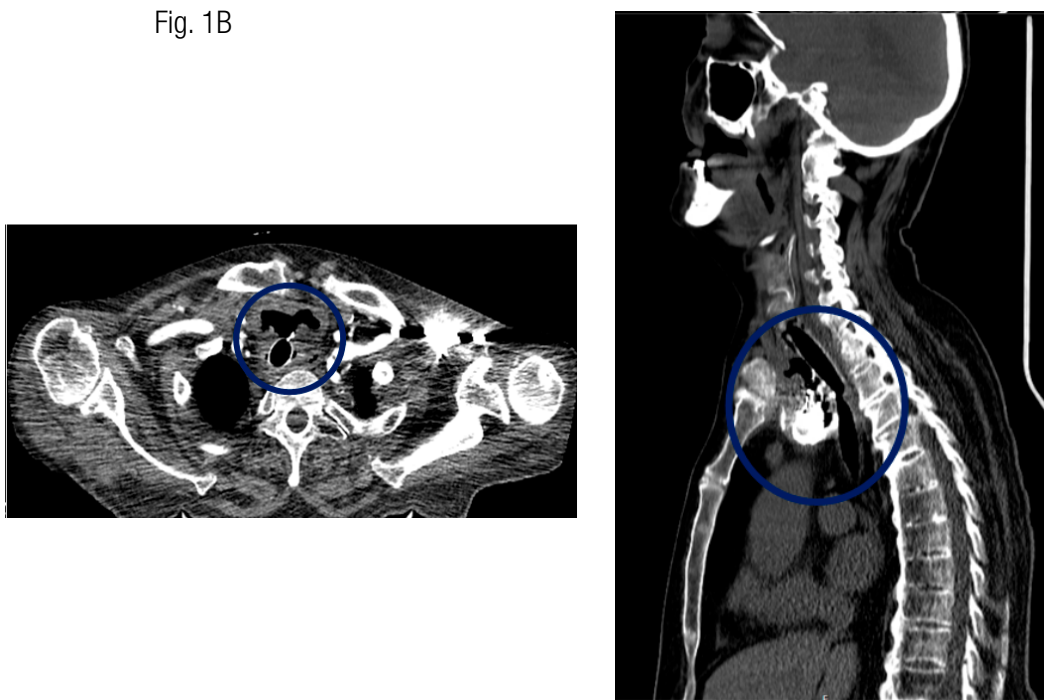

Gabriel Atanásio, Maria Ana Canelas

Serviço de Medicina Interna, Centro Hospitalar Vila Nova de Gaia/Espinho, Porto, Portugal 